\title{
Symptom prevalence and severity in a general practice population
}

\author{
J. G. INGHAM AND P. McC. MILLER
}

From the Medical Research Council Unit for Epidemiological Studies in Psychiatry, Royal Edinburgh Hospital, Edinburgh

SUMMARY The prevalence of symptoms in the community is sometimes used as an index of untreated morbidity. However, such an index can be very misleading unless it makes allowance for differences in symptom severity between declared and undeclared patients. Recent attenders at one health centre were compared with controls who had not seen their GPs for at least three months. Comparisons of symptom severity were made between attenders who had reported one or more of seven selected symptoms and non-attenders who said they were troubled by the same symptoms. For the symptoms selected, it was found that a high proportion of sufferers in both groups were of at least two months' chronicity. Prevalence rates of up to $33 \%$ for backache and tiredness in older women were found in non-attending controls, but symptom severity was significantly less than in patients who had recently consulted their doctors with the same symptom. Symptoms were both more prevalent and more severe among women than among men. It seemed unlikely, however, that this difference could explain the higher consultation rates for women, because the same excess of women over men persisted among consulters. It seems that for these symptoms increasing severity is associated with an increasing probability of attending the surgery but that the symptom functions more often as a background factor than as a precipitant.

The treatment and prevention of illness depend upon bringing together the patients or potential patients and the services they need. Enthusiasts in preventive medicine and epidemiology have advocated screening to seek out those who are in the early stages of illness and who either do not realise it or for some other reason do not seek help themselves. Screening procedures are expensive, however, and inevitably the question of cost-effectiveness arises. Elaborate screening procedures have often been introduced without attempting to demonstrate their effectiveness (Cochrane, 1971), and for some diseases early intervention seems to do little to alter the ultimate prognosis. The alternative is to rely upon the patient to be impelled to seek help because of the discomfort and distress caused by the disease. Commonsense suggests that this is the predominant influence on people to seek treatment or prevention of further deterioration, and it is therefore surprising that so little attention has been given to the effectiveness of symptoms as a stimulus to seeking medical advice.
The symptoms of illness in its early stages are often mild. There is much evidence that general morbidity, using symptom prevalence as an index, is remarkably high, and rarely leads to medical help-seeking (Wadsworth \& Ingham, 1978). In one inquiry (Banks et al., 1975; Beresford et al., 1977) a group of women studied for a period of four weeks reported symptoms on an average of 10 days out of the 28 , but there was only one patient-initiated consultation in 37 symptom episodes. Results of this kind can be misleading, however. Undeclared symptoms may be so mild and unobtrusive as to be indistinguishable from the discomforts and distresses of everyday life that beset us all from time to time, but do not signal the presence of illness. We will make the assumption that the more subjectively severe the symptom, the more likely it is to indicate that the patient is in need of medical help. This may not always be true in individual cases but in the absence of other information it seems the most reasonable assumption to make. Certainly, before symptom prevalence rate can be used as an index of untreated morbidity, it is 
necessary to make allowance for symptom severity. We need to know how the undeclared symptoms compare in severity with those of the help-seekers.

\section{Material and methods}

The study was part of a larger survey designed to investigate the determinants of consulting behaviour in a population of patients registered in one health centre with a catchment area comprising one clearly defined district of a New Town in Scotland. Because it was a New Town, the population was skewed towards the younger age groups, compared with the general population of the country. The study was confined to adults aged 16-75.

Comparison was made between recent attenders with new episodes of illness and controls who had not recently consulted their GPs. During one year a random sample of new episode consulters was drawn daily from those attending the health centre. Sampling rates were one in six for females and one in four for males. For each patient there was a control of the same sex and age group selected at random from the list of registered patients, eliminating those who, according to health centre records, had attended within the previous three months.

\section{Interviews}

Patients visiting their GPs were interviewed on arrival at the health centre by an interviewer trained to use a standard procedure. The interviewers were carefully supervised to ensure that the criterion for a new episode consulter was consistently applied. The basic structure of the interview is shown in the Figure. Those who met the criterion were questioned further about their symptoms. Firstly, there was a general question designed to elicit what they themselves thought was the main reason for the consultation. This was 'What have you come about this time?', supplemented by 'How does it affect you?; what are the symptoms?; anything else?', as appropriate. For any of the seven target symptoms that had not been elicited by the general question, there was then a specific question, 'Have you got any of these troubles?'. A positive answer for any symptom provoked a further question, 'Are you going to ask

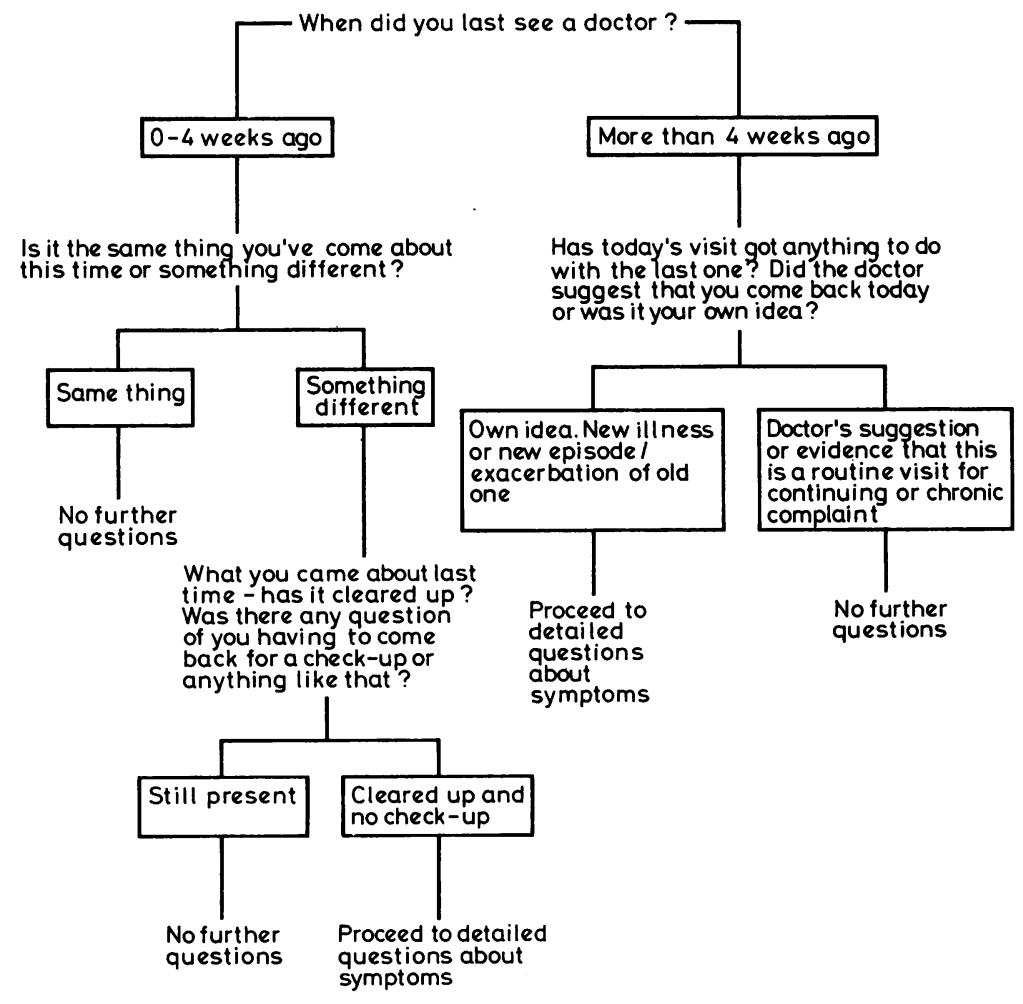

Figure Health centre interview. 
the doctor about this today?'. The selected target symptoms were backache, tiredness, anxiety, headache, depression, irritability, and dizziness. Interviewers were given careful guidance on dealing with borderline cases and they were encouraged to ask supplementary questions if there was real doubt about whether a symptom bothered the patient or whether he or she regarded it as a normal discomfort.

Approximately $93 \%$ of attenders were interviewed successfully at the health centre, as estimated from a random sample of six of the 52 weeks covered by the study, and $29.7 \%$ of these were eligible for inclusion in the sample to be interviewed subsequently at home. The refusal rate for this first interview was $5.4 \% ; 0.8 \%$ were missed for other reasons.

Assuming that the proportions eligible and sampled would have been the same among those not interviewed at the health centre and among those who were willing to be sampled, it is possible to calculate lapse rates based upon the total sample that should have been obtained. On this basis the overall refusal rate was $18.4 \%$, and $73.0 \%$ of the sample were interviewed successfully at home. The rest were accounted for by people missed at the health centre $(1 \cdot 1 \%)$, lapsed because they had not been interviewed within the stipulated 14 days of the consultation $(6.3 \%)$, and moved or incompletely interviewed $(1 \cdot 1 \%)$.

Of the controls selected first, $56.0 \%$ were interviewed successfully, $9.9 \%$ were unwilling to co-operate, and $9.9 \%$ were untraced. The rest had moved too far afield to be visited, or were found to have visited their doctors between selection into the sample and the home visit. Controls not interviewed were replaced by others also selected at random.

Patients and controls were interviewed at home by a trained Medical Research Council interviewer as soon as possible after the initial health centre visit.
The interview was extensive and employed a range of techniques, but those reported here took only a few minutes and comprised severity scales for each of the seven target symptoms. The scales had been tried in earlier pilot studies (Ingham and Miller, 1976a; 1976b) and comprised five statements for each symptom, graded by severity (see Appendix). Scales were presented in two forms: pair comparison, and visual analogue using a $20 \mathrm{~cm}$ line. A further set of seven visual analogue scales required the subjects to rate the degree of unpleasantness associated with each of the symptoms, as experienced by them during the past month.

\section{Results}

The percentages declaring symptoms at each of several levels are shown in Table I. As others have found, a remarkably high proportion of the general population admit to being troubled by symptoms and yet have not sought medical help in the recent past. Some are chronic or recurrent sufferers who have previously sought help, but even excluding those, prevalence rates are high $(2 \cdot 8 \%$ to $32 \cdot 3 \%)$, particularly among older women. For all symptoms, women have higher prevalence rates than men, as is generally found.

The point at issue is whether control subjects who admit the presence of a symptom rate it, on average, as less severe than patients who have recently consulted their doctors with the same symptoms. Both patients and controls were divided into seven groups according to whether they admitted the presence of the symptom or not at each of several levels. These were: not troubled at all; troubled but have not told the doctor; troubled and have told the doctor (patients only-present consultation); troubled and have told the doctor at some time in the

Table 1 Symptom prevalence(\%)

\begin{tabular}{|c|c|c|c|c|c|c|c|c|c|c|c|c|c|c|}
\hline \multirow[b]{5}{*}{ Age at 1 Jan 1976} & & & \multirow{2}{*}{\multicolumn{3}{|c|}{$\begin{array}{l}\text { Consulters } * \\
\text { Aged } 36 \text { and under } \\
\text { Aged over } 36\end{array}$}} & \multirow{2}{*}{\multicolumn{2}{|c|}{$\begin{array}{l}n \text { (males) } \\
221 \\
121\end{array}$}} & \multirow{2}{*}{\multicolumn{2}{|c|}{$\begin{array}{l}n \text { (females) } \\
266 \\
101\end{array}$}} & & \multirow{4}{*}{\multicolumn{2}{|c|}{ Irritability }} & & \\
\hline & & & & & & & & & & & & & & \\
\hline & \multicolumn{11}{|c|}{ Consulters (surgery interview) } & & & \\
\hline & \multicolumn{2}{|c|}{ Backache } & \multicolumn{2}{|c|}{ Tiredness } & \multicolumn{2}{|c|}{ Anxiety } & \multicolumn{2}{|c|}{ Headache } & \multicolumn{2}{|c|}{ Depression } & & & \multicolumn{2}{|c|}{ Dizziness } \\
\hline & $\boldsymbol{M}$ & $\boldsymbol{F}$ & $M$ & $\boldsymbol{F}$ & $\boldsymbol{M}$ & $\boldsymbol{F}$ & $M$ & $\boldsymbol{F}$ & $\boldsymbol{M}$ & $\boldsymbol{F}$ & $\boldsymbol{M}$ & $\boldsymbol{F}$ & $\boldsymbol{M}$ & $\boldsymbol{F}$ \\
\hline \multirow[t]{3}{*}{$\begin{array}{l}36 \text { and under } \\
\text { Over } 36\end{array}$} & $\begin{array}{l}26 \cdot 9 \\
28 \cdot 1\end{array}$ & $\begin{array}{l}35 \cdot 3 \\
42 \cdot 6\end{array}$ & $\begin{array}{l}25 \cdot 6 \\
33 \cdot 9\end{array}$ & $\begin{array}{l}42 \cdot 9 \\
66 \cdot 3\end{array}$ & $\begin{array}{l}15 \cdot 0 \\
23 \cdot 1\end{array}$ & $\begin{array}{l}31 \cdot 7 \\
49 \cdot 5\end{array}$ & $\begin{array}{l}26 \cdot 8 \\
26 \cdot 4\end{array}$ & $\begin{array}{l}40 \cdot 2 \\
44 \cdot 6\end{array}$ & $\begin{array}{l}11 \cdot 0 \\
12 \cdot 4\end{array}$ & $\begin{array}{l}22 \cdot 0 \\
36 \cdot 6\end{array}$ & $\begin{array}{l}17 \cdot 2 \\
19 \cdot 0\end{array}$ & $\begin{array}{l}27.9 \\
40.6\end{array}$ & $\begin{array}{l}11 \cdot 8 \\
11 \cdot 6\end{array}$ & $\begin{array}{l}20 \cdot 3 \\
25 \cdot 7\end{array}$ \\
\hline & \multicolumn{14}{|c|}{ Controls (home interview) } \\
\hline & \multicolumn{2}{|c|}{ Backache } & \multicolumn{2}{|c|}{ Tiredness } & \multicolumn{2}{|c|}{ Anxiety } & \multicolumn{2}{|c|}{ Headache } & \multicolumn{2}{|c|}{ Depression } & \multicolumn{2}{|c|}{ Irritability } & \multicolumn{2}{|c|}{ Dizziness } \\
\hline $\begin{array}{l}36 \text { and under } \\
\text { Over } 36\end{array}$ & $\begin{array}{l}14 \cdot 0 \\
19 \cdot 0\end{array}$ & $\begin{array}{l}23 \cdot 6 \\
32 \cdot 3\end{array}$ & $\begin{array}{l}17 \cdot 6 \\
15 \cdot 7\end{array}$ & $\begin{array}{l}28 \cdot 2 \\
28 \cdot 3\end{array}$ & $\begin{array}{l}12 \cdot 2 \\
14 \cdot 0\end{array}$ & $\begin{array}{l}19 \cdot 6 \\
24 \cdot 2\end{array}$ & $\begin{array}{l}11 \cdot 8 \\
13 \cdot 2\end{array}$ & $\begin{array}{l}24 \cdot 8 \\
23 \cdot 2\end{array}$ & $\begin{array}{l}6 \cdot 8 \\
9 \cdot 1\end{array}$ & $\begin{array}{l}13 \cdot 4 \\
17 \cdot 2\end{array}$ & $\begin{array}{l}12.4 \\
10.7\end{array}$ & $\begin{array}{l}15 \cdot 2 \\
16 \cdot 2\end{array}$ & $\begin{array}{l}2 \cdot 8 \\
4 \cdot 9\end{array}$ & $\begin{array}{l}5 \cdot 8 \\
7 \cdot 1\end{array}$ \\
\hline
\end{tabular}

* There are the same numbers of male controls but because of administrative errors there are three fewer female controls. 
past. A three-way analysis of variance (group $\times \operatorname{sex} \times$ age) revealed highly significant effects of group and sex, but the frequency distributions were highly skewed and some significant interactions made it difficult to interpret the main effects. The comparisons of greatest interest in the present context were those between patients and controls who had admitted the presence of the same symptoms. Fortunately these subgroups yielded reasonably symmetrical distributions and this enabled us to use parametric tests of significance on comparisons between patients and controls.

Table 2 compares the mean scores of patients declaring each symptom (that is, patients who informed the interviewer that they intended to tell the doctor about it) and controls who declared the same symptom (that is, admitted its presence at the home interview). On the symptom severity scales, both pair comparison and visual analogue, there is hardly any evidence that patients have, in general, more severe symptoms than controls who declare the presence of the same symptoms. On only three of the 14 scales do patients have significantly higher symptom scores $(P<0.05,2-T a i l)$, and in six the differences are in the opposite direction, although not significantly. All scales revealed significant differences between the sexes (higher severity in women than men) and in some cases there were significant interactions between age and sex. Separate comparisons for younger and older men and women also showed little evidence of greater severity in patients. In the younger age group, only five of the 28 comparisons were significant in that direction and 10 were in the opposite direction, three of them significantly. There were no significant differences for the older age group, partly perhaps because of small numbers.

When we come to consider the amount of distress associated with each symptom, a different picture emerges. For all symptoms except headache and dizziness patients reported significantly more unpleasantness than controls. The age/sex groups showed the same tendency but statistical significance was not often reached, partly because of smaller numbers.

Although at first sight these results appear unambiguous, there are possible areas of uncertainty. Those who declared the presence of a symptom by answering positively to a question such as 'Are you troubled by backache?' might have included both chronic and acute sufferers. Chronic sufferers among the controls might have consulted at some time in the past (more than three months ago) and might have decided that frequent consultation was unnecessary, and consulters with acute symptoms might have recovered to some extent before the home interview at which symptom severity was assessed.
Table 2 Comparison ofmean symptom scores for patients who said they were declaring the symptom to the doctor and controls who admitted the presence of the symptom at home interview

\begin{tabular}{|c|c|c|c|c|}
\hline Symptom & & Patients & Controls & $P_{2-T a i l}$ \\
\hline \multicolumn{5}{|l|}{ BACKACHE } \\
\hline & Pair comparisons & $3 \cdot 16$ & $3 \cdot 38$ & \multirow{4}{*}{$\begin{array}{l}\text { NS } \\
\text { NS } \\
<0.01\end{array}$} \\
\hline & Visual analogue & $7 \cdot 44$ & 7.66 & \\
\hline & Visual analogue (distress) & $7 \cdot 13$ & 5.43 & \\
\hline & No. of subjects & 127 & 149 & \\
\hline \multicolumn{5}{|l|}{ TIREDNESS } \\
\hline & Pair comparisons & $2 \cdot 64$ & $2 \cdot 61$ & \\
\hline & Visual analogue & $6 \cdot 94$ & $6 \cdot 18$ & NS \\
\hline & Visual analogue (distress) & $7 \cdot 05$ & 5.41 & $<0.01$ \\
\hline & No. of subjects & 188 & \multicolumn{2}{|l|}{161} \\
\hline \multicolumn{5}{|l|}{ ANXIETY } \\
\hline & Pair comparisons & 3.44 & 3.08 & $<0.10$ \\
\hline & Visual analogue & $8 \cdot 14$ & 6.77 & $<0.03$ \\
\hline & Visual analogue (distress) & $9 \cdot 40$ & 6.64 & $<0.01$ \\
\hline & No. of subjects & 100 & \multicolumn{2}{|l|}{119} \\
\hline \multicolumn{5}{|l|}{ HEADACHE } \\
\hline & Pair comparisons & $2 \cdot 51$ & $2 \cdot 70$ & NS \\
\hline & Visual analogue & 5.45 & 5.86 & NS \\
\hline & Visual analogue (distress) & $7 \cdot 38$ & $7 \cdot 40$ & NS \\
\hline & No. of subjects & 154 & \multicolumn{2}{|l|}{131} \\
\hline \multicolumn{5}{|l|}{ DEPRESSION } \\
\hline & Pair comparisons & 3.08 & 2.69 & \\
\hline & Visual analogue & 7.59 & 5.67 & $<0.01$ \\
\hline & Visual analogue (distress) & $10 \cdot 86$ & $7 \cdot 59$ & $<0.01$ \\
\hline & No. of subjects & 70 & 79 & \\
\hline \multicolumn{5}{|c|}{ IRRITABILITY } \\
\hline & Pair comparisons & 3.59 & $3 \cdot 11$ & $<0.07$ \\
\hline & Visual analogue & $8 \cdot 01$ & $6 \cdot 78$ & $<0.05$ \\
\hline & Visual analogue (distress) & $8 \cdot 62$ & $6 \cdot 51$ & $<0.01$ \\
\hline & No. of subjects & 81 & 96 & \\
\hline \multicolumn{5}{|l|}{ DIZZINESS } \\
\hline & Pair comparisons & $2 \cdot 54$ & $2 \cdot 79$ & NS \\
\hline & Visual analogue & $5 \cdot 29$ & 5.47 & NS \\
\hline & Visual analogue (distress) & $5 \cdot 50$ & $5 \cdot 12$ & NS \\
\hline & No. of subjects & 83 & 34 & \\
\hline
\end{tabular}

All subjects were asked whether they had sought help for the symptom at any time in the past; among the controls, from nine to 55 according to symptom said they had. Their mean scores on the symptom scales were somewhat higher than the rest.

Fifty per cent of the consulters were seen within four days of the consultation and virtually all of them within 14 days. They had all been asked again at the home interview whether they were troubled by the symptoms and some (from 14 to 58 according to 
symptom) said they were not, despite the fact that they had just attended the health centre and complained of it.

Table 3 compares mean symptom scores as in Table 2, but excluding patients who at home interview no longer admitted the presence of the symptom and controls who had sought help for it in the past. Clearly, provided these two groups are excluded, non-consulting controls with symptoms do indeed seem to have them less severely than patients who have consulted their doctors with the same symptoms, and seem to express much less distress. There is a possibility, however, that this generalisation may apply only to certain age/sex

Table 3 Comparison of mean symptom scores for patients (who said they were declaring the symptom to the doctor and who still admitted the presence of symptom at home interview) and controls with symptoms (admitted symptom at home interview and had not sought help)

\begin{tabular}{|c|c|c|c|c|}
\hline Symptom & & Patients & Controls & $P_{\text {2-Tail }}$ \\
\hline \multirow[t]{2}{*}{ BACKACHE } & $\begin{array}{l}\text { Pairs } \\
\text { Lines } \\
\text { Distress }\end{array}$ & $\begin{array}{l}3.69 \\
8 \cdot 32 \\
7 \cdot 93\end{array}$ & $\begin{array}{l}3 \cdot 13 \\
7 \cdot 22 \\
4 \cdot 99\end{array}$ & $\begin{array}{l}<0.01 \\
<0.04 \\
<0.01\end{array}$ \\
\hline & No. of subjects & 94 & 94 & \\
\hline \multirow[t]{2}{*}{ TIREDNESS } & $\begin{array}{l}\text { Pairs } \\
\text { Lines } \\
\text { Distress }\end{array}$ & $\begin{array}{l}3.09 \\
7.98 \\
8.47\end{array}$ & $\begin{array}{l}2 \cdot 57 \\
6 \cdot 05 \\
5 \cdot 23\end{array}$ & $\begin{array}{l}<0.02 \\
<0.01 \\
<0.01\end{array}$ \\
\hline & No. of subjects & 130 & 138 & \\
\hline \multirow[t]{2}{*}{ ANXIETY } & $\begin{array}{l}\text { Pairs } \\
\text { Lines } \\
\text { Distress }\end{array}$ & $\begin{array}{r}3.83 \\
9 \cdot 22 \\
10.95\end{array}$ & $\begin{array}{l}2 \cdot 78 \\
6 \cdot 20 \\
6 \cdot 54\end{array}$ & $\begin{array}{l}<0.01 \\
<0.01 \\
<0.01\end{array}$ \\
\hline & No. of subjects & 76 & 85 & \\
\hline \multirow[t]{2}{*}{ HEADACHE } & $\begin{array}{l}\text { Pairs } \\
\text { Lines } \\
\text { Distress }\end{array}$ & $\begin{array}{l}3 \cdot 23 \\
6 \cdot 67 \\
9 \cdot 12\end{array}$ & $\begin{array}{l}2 \cdot 37 \\
5 \cdot 44 \\
6 \cdot 36\end{array}$ & $\begin{array}{l}<0.01 \\
<0.01 \\
<0.01\end{array}$ \\
\hline & No. of subjects & 97 & 84 & \\
\hline \multirow[t]{2}{*}{ DEPRESSION } & $\begin{array}{l}\text { Pairs } \\
\text { Lines } \\
\text { Distress }\end{array}$ & $\begin{array}{r}3 \cdot 39 \\
8 \cdot 57 \\
11 \cdot 71\end{array}$ & $\begin{array}{l}2.66 \\
5.48 \\
7.05\end{array}$ & $\begin{array}{l}<0.02 \\
<0.01 \\
<0.01\end{array}$ \\
\hline & No. of subjects & 56 & 58 & \\
\hline \multirow[t]{2}{*}{ IRRITABILITY } & $\begin{array}{l}\text { Pairs } \\
\text { Lines } \\
\text { Distress }\end{array}$ & $\begin{array}{l}4.03 \\
8.97 \\
9 \cdot 92\end{array}$ & $\begin{array}{l}3.00 \\
6.69 \\
6.45\end{array}$ & $\begin{array}{l}<0.01 \\
<0.01 \\
<0.01\end{array}$ \\
\hline & No. of subjects & 59 & 87 & \\
\hline \multirow[t]{2}{*}{ DIZZINESS } & $\begin{array}{l}\text { Pairs } \\
\text { Lines } \\
\text { Distress }\end{array}$ & $\begin{array}{l}3 \cdot 26 \\
7 \cdot 13 \\
7 \cdot 28\end{array}$ & $\begin{array}{l}2 \cdot 64 \\
4 \cdot 88 \\
4 \cdot 48\end{array}$ & $\begin{array}{l}<0.04 \\
<0.01 \\
<0.01\end{array}$ \\
\hline & No. of subjects & 46 & 25 & \\
\hline
\end{tabular}

groups. Results were clear-cut only for younger women, but the uncertainty may arise from the small number in some cells at this level of analysis. The exclusion of recovered patients accounted for much of the difference between Tables 2 and 3 , but the exclusion of controls who had sought help did somewhat reduce the mean scores of the controls.

Comparisons between patients and controls with symptoms may be invalidated if, as could be so, controls comprise mainly chronic sufferers and patients mainly acute sufferers. Table 4 shows this to be partly true, and there is a significant difference in chronicity between patients and controls. In both groups there are many intermediate cases who place the onset of their symptoms from between two and 12 months before the interview.

Separate comparisons between patients and controls at each level of chronicity are shown in Table 5. One thing clearly shown is that, as far as these selected symptoms are concerned, this is largely a study of chronic and intermediate patients and controls. Relatively few subjects reported onsets less than a month before the interview. This is particularly obvious for psychological symptoms. Furthermore, there are no statistically significant differences in symptom scores between patients and controls in the acute group, although this may be due, in part at least, to the small numbers. Nearly all symptoms differentiate significantly between patients and controls in the intermediate group, with patients, as predicted, reporting higher severity. The exception, dizziness, is very infrequent in this group for both patients and controls. For chronic sufferers as well, there is a marked tendency for patients to report higher severity, but fewer of the differences reach statistical significance. Where there is a significant difference for intermediates and not for the chronic sufferers, it appears to be because the latter rate their symptoms as less severe. One striking exception was anxiety: for both visual analogue lines and distress ratings, the variance among chronic patients was exceptionally high. There was a slight tendency for chronic patients and controls to rate their symptoms as less severe than the intermediates but this tendency was less marked for the controls.

\section{Discussion}

Individuals who declared the presence of a target symptom were, in the main, sufferers of at least two months' chronicity. The patients included in the analysis were those who had declared their intention of telling the doctor about the symptom; from that it may be inferred that the presence of the symptom concerned had entered into their decision to consult in the first place. However, it was not necessarily the 
Table 4 Numbers of patients and controls at each level of chronicity

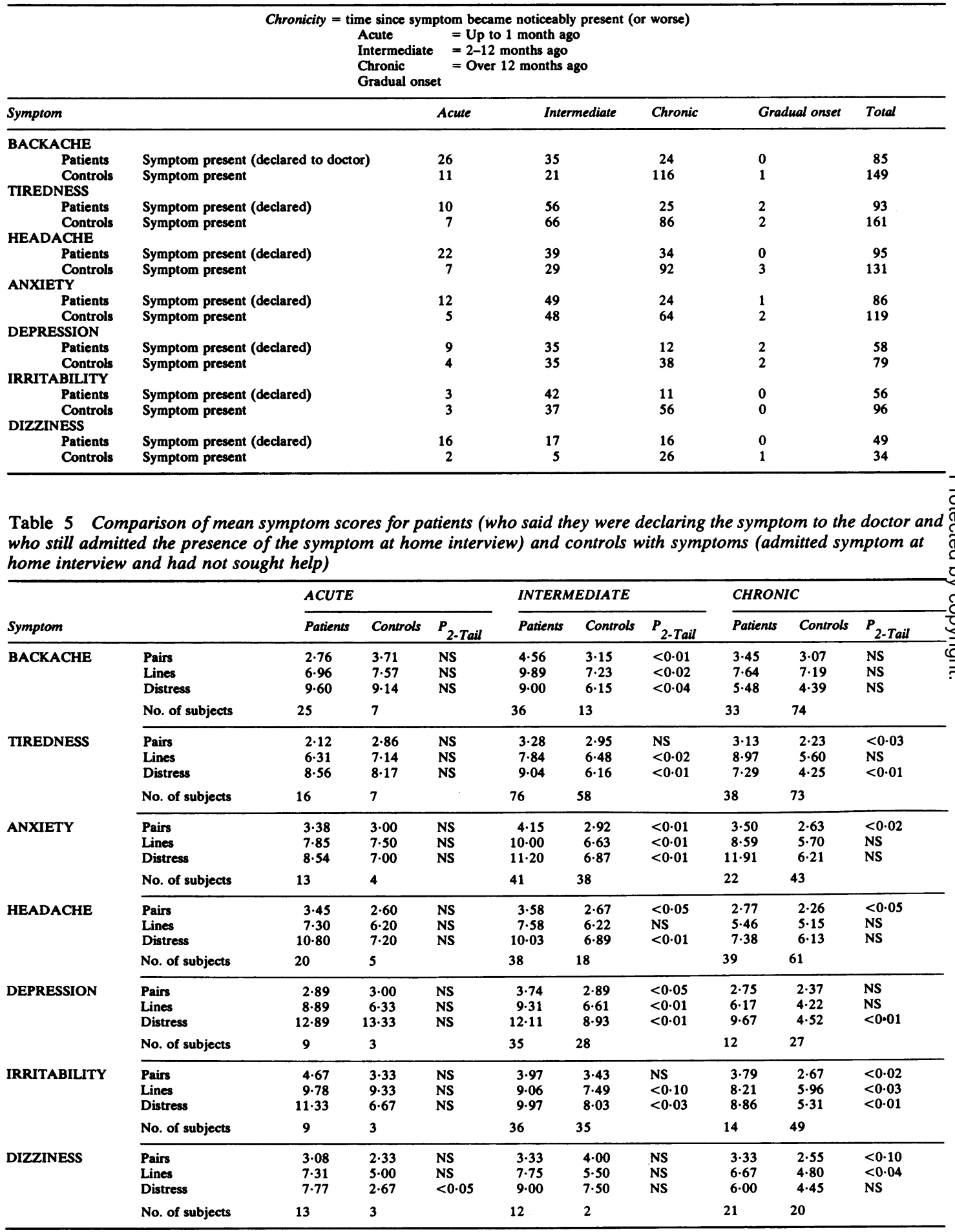


main reason for the consultation, and patients had not usually stated spontaneously that one of the target symptoms was the reason for the visit. The proportion of symptoms mentioned spontaneously was particularly low for the psychological symptoms, anxiety, depression, and irritability, but even backache and headache were declared spontaneously by only about half of those who admitted having them and who had declared their intention of mentioning them to the doctor.

On the whole, for most of the patients we have included in the analysis, the target symptoms may be said to have influenced the patients' self-referral, although other symptoms and problems had probably been the determining factors that finally precipitated the consultation. Those who had declared a symptom spontaneously as the reason for the health centre visit had mean scores on the symptom scale remarkably similar to those who had responded positively only to specific questioning (Table 3).

Prevalence rates are clearly higher among consulters than among controls. It is possible that the act of consultation induces a set in the patient to respond positively to questions about symptoms, but consulters who do respond positively show evidence of greater severity than controls, even on scales that have been designed to minimise the influence of irrelevant sets. Consultation-induced positive sets cannot be entirely ruled out but it seems likely that symptoms as assessed by our techniques do play some part in causing people to consult their doctors. At the same time, it should be noted that less than a third of patients declaring a symptom had an acute onset or exacerbation within the previous month. For psychological symptoms the proportion was even smaller. With acute onset or exacerbation, having the symptom may, in part at least, have precipitated the consultation, whereas when the onset was more than one month before the consultation it was more likely to have contributed as a background factor. The proportion of acute onsets among controls with symptoms was very small compared with that among consulters (Table 4) and the proportion of chronics was large. Furthermore, both chronic and intermediate (two to 12 months) control subjects had lower average severity scores than consulters. It would therefore be misleading to take symptom prevalence to indicate the size of the reservoir of untreated morbidity. Untreated cases defined symptomatically differed from health centre attenders. The greater proportion were chronic sufferers from symptoms that were relatively mild according to our severity scales.

Severity and chronicity have not usually been taken into account in other studies. Dohrenwend and Crandell (1970) showed that the high prevalence of psychiatric symptomatology in a community sample was due mainly to a high frequency of less serious symptoms. However, it was not the severity of individual symptoms they considered, but type of symptom. Similarly, Wing et al. (1978), using the present state examination and index of definition, showed that the majority of women with symptoms in a general population did not have sufficiently well-defined disorders to make a diagnosis possible. Furthermore, those who were diagnosable, most of them with depressive disorders, had on average fewer and less severe symptoms than either inpatients or outpatients with the same diagnoses.

The present study shows the same thing for specific symptoms, and it has also revealed the high proportion of chronic symptoms among controls. One of the factors that determined our choice of physical symptom was frequency among GP attenders. It would be interesting to see whether less frequent symptoms also tend to be chronic when they occur among non-consulting controls.

The symptoms we have been studying tend to be more prevalent among women than among men, for consulters and controls alike, and most women are more likely to tell their doctors about them. Backache is an exception for consulters but not for controls (Table 1). Many investigations have shown that women are in general more ready to admit to having symptoms either to their doctors or to other health professionals, although it is impossible to say whether they actually experience them more severely. It is unlikely that the higher female prevalence rate in the general population explains the higher consultation rates for women, because the same excess of women over men persists among consulters.

Our symptom scales reveal only some aspects of subjective severity, not necessarily those that are most closely related to early pathology, but we shall progress only if we are able to define severity operationally and then see how our defined variables relate to outcome and other aspects of pathology. The early detection of illness by its symptoms is limited by its very nature. Illness cannot be detected by symptoms indistinguishable from ordinary everyday distresses or discomforts, but we must seek ways of improving discrimination of these symptoms. Meanwhile, it is useful to know more precisely the expressed characteristics of symptoms that do discriminate to some degree between consulters and controls.

\section{Conclusions}

1. Symptom prevalence rates assessed in an orthodox way vary from $2 \%$ (dizziness in young men) 
to $33 \%$ (backache and tiredness in older women) in non-consulting controls.

2. However, when proper account is taken of symptom severity, chronicity, previous non-recent consultation, and delay between consultation and interview, it is apparent that symptoms reported by controls are on average less severe than those reported by people who have recently consulted their doctors.

3. Non-consulting controls with symptoms contain a high proportion of chronic sufferers when compared with consulters, but the chronic sufferers also tend to report their symptoms as less severe.

4. For the patients who had visited their doctors declaring one or other of the symptoms, the severity of the symptom seems likely to have increased the probability of their attending the surgery, but more often as a background factor than as a precipitant.

We thank the patients and staff of Craigshill Health Centre.

Reprints from Dr. J. G. Ingham, MRC Unit for Epidemiological Studies in Psychiatry, Royal Edinburgh Hospital, Edinburgh.

\section{References}

Banks, M. H., Beresford, S. A. A., Morrell, D. C., Waller, J. J., and Watkins, C. J. (1975). Factors influencing demand for primary medical care in women aged $20-44$ years: a preliminary report. International Journal of Epidemiology, 4, 189-195.

Beresford, S. A. A., Waller, J. J., Banks, M. H., and Wale, C. J. (1977). Why do women consult doctors? Social factors and the use of the G.P. British Journal of Preventive and Social Medicine, 31, 220-226.

Cochrane, A. C. (1971). Effectiveness and Efficiency; random reflections on health services. Nuffield Provincial Hospitals Trust: London.

Dohrenwend, B. P., and Crandell, D. L. (1970). Psychiatric symptoms in community, clinic and mental hospital groups.American Journal of Psychiatry, 126, 1611-1621.

Ingham, J. G., and Miller, P. McC. (1976a). The concept of prevalence applied to psychiatric disorders and symptoms. Psychological Medicine, 6, 217-225.

Ingham, J. G., and Miller, P. McC. (1976b). The determinants of illness declaration. Journal of Psychosomatic Research, 20, 309-316.

Wadsworth, M., and Ingham, J. G. (1979). How society defines sickness: illness behaviour and consultation. In Psychosomatic Approaches to Medicine, 1. Edited by M. J. Christie and P. G. Mellet. (In press).

Wing, J. K., Mann, S. A., Leff, J. P., and Nixon, J. M. (1978). The concept of a 'case' in psychiatric population surveys. Psychological Medicine, 8, 203-217.

\section{Appendix}

Statements used in symptom scales

BACKACHE

My back never bothers me at all.

My back hardly ever bothers me.

I often have a twinge of pain in my back.

Often I have a lot of pain in my back.

I have very bad backache all the time.

\section{TIRED NESS}

I hardly ever get tired.

I generally feel a little tired by the end of the day.

I always feel very tired by the end of the day.

I feel very tired most of the time.

I am always worn out and exhausted.

ANXIETY

I never worry about anything.

I get a bit worried occasionally.

I often get worried about things.

I tend to worry a great deal.

I am always in a state of terrible worry and anxiety.

HEA D ACH E

I never have headaches.

Very occasionally I have a slight headache.

Quite often I have a fairly bad headache.

I get a lot of severe headaches.

I have constant very bad headaches that are almos unbearable.

\section{DEPRESSION}

I never feel unhappy.

I sometimes feel a bit unhappy.

I am quite often in low spirits.

I frequently feel very miserable.

I always feel very miserable and depressed.

IRRIT A BILITY

I never feel irritable at all.

Occasionally I feel a bit irritable.

I sometimes feel rather irritable.

Often I feel very irritable.

I feel extremely irritable most of the time.

\section{DIZZINESS}

I never feel even slightly dizzy.

Very occasionally I feel a wee bit dizzy.

Sometimes I feel a bit dizzy.

I quite often feel dizzy.

I usually feel very dizzy. 